\title{
Application of Microlecture for the Pharmacy Practical Instrumental Experiment Teaching
}

\author{
Sheng $Y u^{1, a}$, Yuan Guangxin ${ }^{1, b, *}$, Niu Jiamu ${ }^{2, c}$, Bai $Y u^{3.4 . d}$ \\ ${ }^{1}$ College of Pharmacy, Beihua University, Jilin, Jilin, China \\ ${ }^{2}$ Research Department, Beihua University, Jilin, Jilin, China \\ ${ }^{3}$ Department of chemistry, Jinlin Medical College, Jilin, Jilin, China \\ ${ }^{4}$ College of Pharmacy, Jinlin University, Changchun, Jilin, China \\ a383165810@qq.com, byuanguangxin2007@163.com, b17287598@qq.com, \\ dbaiyu2007@163.com \\ *Corresponding author: yuanguangxin2007@163.com
}

Keywords: Micro-lesson, Pharmacy Practical Instrumental, Experiment Teaching

Abstract. The analysis experiment of pharmacy practical instrumental is a very important part of pharmacy practical instrumental analysis course. However, due to the limited equipment, limiting short hours and other conditions, sometimes, we cannot achieve the intended purpose. Micro-lesson is one of the most popular teaching methods nowadays, it is a video lesson which recorded the teaching activities based on one teaching point. If we combine the advantages of micro-lesson and analysis experiment of pharmacy practical instrumental, we will not only improve the student's understanding of experimental course but also mobilize their enthusiasm for learning. This paper describes the importance, the methods and the prospects of micro-lesson used in the analysis experiment of pharmacy practical instrumental, provide the useful experience for the teaching reform.

\section{Introduction}

All manuscripts must be in English, also the table and figure texts, otherwise we cannot publish your "Pharmacy Practical Instrumental Analysis" as a professional compulsory courses feat for the characteristics and needs of Pharmacy in our school, it mainly focuses on the basic fundamental, structure and operation method of the variety of instruments that pharmacy disciplines involved. So the analysis experiment of pharmacy practical instrumental is very important, we can further improve the theoretical knowledge that students learned in class, and also grasp the basic operation and maintenance tips. Previous experiments are taking teaching teachers to talk about the test content and the specific steps, then completed by the students themselves experiment evaluated by the teacher, but the teacher only taught experimental content, was very boring, and because of the insufficient number of instruments, limited hours, so that each student cannot finish the experiment throughout the whole progress ${ }^{[1]}$. Therefore, most students don ${ }^{`}$ know how to finish the experiment after class, micro-class will solve this problem.

\section{The significance of introducing micro-class into the analysis experiment of pharmacy practical instrumental}

Micro-class is short for "miniature video class", which is based on video teaching methods and special knowledge points ${ }^{[2,3]}$. The core of micro-class is micro video, no longer than 15 minutes. Specifically, micro-class has the following important application values ${ }^{[4]}$.

\section{Popular and vivid}

Micro video impressed the experiment process in the students` mind, whic is easer to understand and remember. The teacher only need some necessary explanations before the experiment, will enable students to have fully understood. For example, after watching the micro video of infrared spectroscopy experiments, the students will clearly see the thickness of the diaphragm made of 
potassium bromide, and the light transmittance will not appear the phenomenon of too large or too small. And also by watching the loading progress of tableting machine, the students can clearly remenber the order of operation to avoid errors occurred ${ }^{[5,6]}$.

\section{Repeat and deepen}

In traditional experimental teaching progress, once one part of the class didn't been understood.it will affect the students` understanding of the experiment`s content directly, and also lead to the experiment's failure.However, micro class will solve this problem. Micro class is video teaching, can be repeated viewing, repeated analysis ${ }^{[7,8]}$. The whole progress of experiment can be repeated again and again.

\section{One to one teaching method}

Dozens of students sutudy with one teacher(one to many), because of different abilities, knowledge structure and different level of understang, will cause different problems. However, if one teacher face to one student, the teaching content, experiment phenomenon and operation progress will be saw clearly through the video.

\section{The methods of introducing micro class into the analysis experiment of pharmacy practical instrumental}

\section{Design teaching objectives}

Briggs believes that instructional design is whole analysis process of learning needs and objectives. The target of pharmacy practical instrument analysis experimental teaching requires students to grasp the analysis methods and skills of instrument analysis, so as to improve students practical ability, innovation and the ability to analyze and solve problems.

\section{Recording the teaching process}

After making the appropriate choice of instructional design in accordance with the teaching objectives, you can record micro course.Before recording, requiring teachers and cameraman communicate well and familiar with the teaching process, design a reasonable allocation of teachers teaching time.

\section{Post-editing}

After the micro class, may not be able to achieve the best teaching effect, the operation process may also need post editing. Therefore, the post-editing is very important. Fistly, repeated review the content of the micro video is necessary. Followed by consideration of making micro class titles, credits. Finally add background music and captions for the micro class video. By editing, landscaping, solve the practical problems appeared in teaching process.

\section{The application prospects of micro class in the analysis experiment of pharmacy practical instrumental}

Nowadays, more and more college students use smart phones, mobile digital products, which changes their reading and learning habits ${ }^{[9,10]}$. Therefore, if they use these electronic devices to read the experiment content after class, it would be a good way to docking with classroom teaching.It will become an extension of classroom teaching, and will also become a new mode of teaching method. Micro class as this type of teaching, is a big reform that can open another area of teaching method. The design and application of micro class, will face many changes. The main body of micro class is teacher, so the ability of design and application is very important.Many companies and researchers are also trying to use all kinds of tools to reduce the difficulty of design. The scientific, technical and artistic of micro class is another challenge of developing. Only solve this problem can improve the teaching effect of experiment ${ }^{[11-13]}$. 


\section{Result and discussion}

The Pharmacy Practical Instrumental Experiment microlecture was applied to the pharmacy undergraduates in our university in 2013, 2014 and 2015. After the microlecture was applied for three years, the implementation results of it were evaluated through the usual observation, questionnaires and interviews.

\section{Increase in the learning interest}

As shown in Table 1, the students' interest in the learning of the course has changed since the application of microlecture.

Table 1 Effects of the pharmacy practical instrumental experiment microlecture on the learning interest $(\mathbf{n}=\mathbf{2 1 8})$

\begin{tabular}{lll}
\hline Learning interest & Number & percentage \\
\hline Improved & 126 & $58.1 \%$ \\
Slightly improved & 83 & $38.0 \%$ \\
No effect & 9 & $3.9 \%$ \\
\hline
\end{tabular}

\section{Improvement of the learning outcomes}

As shown in Table 2, the Pharmacy Practical Instrumental Experiment microlecture could improve the students' learning outcomes and knowledge construction.

Table 2 Effects of the pharmacy practical instrumental experiment microlecture on the learning outcomes $(\mathbf{n}=\mathbf{2 1 8})$

\begin{tabular}{lll}
\hline Learning outcomes & Number & Percentage \\
\hline Improved & 151 & $69.2 \%$ \\
Slightly improved & 63 & $29.1 \%$ \\
No effect & 4 & $1.8 \%$ \\
\hline
\end{tabular}

\section{Conclusion}

Micro class as the new forms of teaching, which is dapper, video-based and relying on network, has great potential ${ }^{[14-16]}$. This paper attempts to introduce micro class into the analysis experiment of pharmacy practical instrumental, to stimulate students initiative and innovation. It will improve the overall quality of teaching and achieve the initial goal of education.

\section{Acknowledgements}

This work was financially supported by BeiHua University Network Teaching Platform Project and Youth teaching Project of BeiHua University.

\section{References}

[1] M. Grew, L.A. Journal of Chemistry Education. 6, 231. (1993)

[2] D. Shieh. The Chronicle of Higher Education. 5, 112. (2009)

[3] Kee T P. The One Minute Lecture. Education in Chemistry. 5, 325. (1995)

[4] T. Seng, C. Hee, F.L. Angela, W. Song. Teaching and Learning with Technology-An Asia-Pacific Perspective. 10, 112. (2001)

[5] M. Lindner, P.A. Proceedings of the 3rd International Micro-learning 2007 Conference. 16, 58. (2007)

[6]D.D.Xu, Z.H.Ou, X.P.Bi. Pharmaceutical Education. 2. (2014)

[7]T.S.Hu, M.Y.Huang, M.Li. Journal of Distance Education. 4. (2013)

[8]L.M.Liang, Q.Q.Zeng, B.H.Zhang. Open Education Research. 1,19. (2013)

[9]X.P.Bi, Z.J.Zhao, S.Hu. Preclinical Medical Education. 12, 13. (2011)

[10]M. Ally. Athabasca: Athabasca University. 525. (2004) 
[11]G.V. Davidson-Shivers, K.L. Rasmussen. NY: M.E.Sharpe, Inc. 621. (2006)

[12]Y. Zhou, L.Q. Zhang, J.M. Lin. Experimental Technology and Management, 27, 93. (2010)

[13]W.J. Orlikowski. Organization Science, 13, 249. (2002)

[14]J.A. Raelin. Academy of Management Learning \& Education, 6, 495. (2007)

[15]A. Sfard. Educational Researcher, 27, 4. (1998)

[16]T.R. Schatzki, K. Knorr Cetina, E. Von Savigny. (Eds.). London: Routledge. 56. (2010) 